\title{
Determination of Trifluoperazine hydrochloride by New Constructed Coated Carbon Selective Electrodes
}

\author{
Aveen K. Mohammed, Ali I. Khaleel \\ Department of Chemistry, College of Science, Tikrit University
}

\section{Article Info}

Received: July, 2019

Revised:July,2019

Accepted:July,2019

\section{Keywords}

Coated Carbon electrode,

Trifluoperazine

hydrochloride,

Potentiometry,

Pharmaceutical preparations.

\section{Corresponding Author}

chemistrysara@yahoo.com

\begin{abstract}
In this research, two coated carbon electrodes were constructed and used for the determination of Trifluoperazine hydrochloride (TFPH) drug. The electrodes were constructed by preparing ion-pair for (TFPH) with phosphotungstic acid (PTA) or phosphomolybdic(PMA) acid using di butyl phthalate (DBP) as a plasticizer and poly vinyl chloride (PVC) as a matrix. These electrodes showed good sensitivity towards TFPH. Optimum temperature range $(25-55 \text { and } 25-50)^{\circ} \mathrm{C}$, limit of detection $\left(4.99 \times 10^{-6}\right.$ and $\left.4.56 \times 10^{-6}\right) \mathrm{M}$,correlation coefficient, (0.9990 and 0.9980), slope (30.67 and 30.26) $\mathrm{mV} /$ decade for TFPH-PTA and for TFPH-PMA electrodes respectively.. Optimum $\mathrm{pH}$ range (2.7-6.6), the life time (48) days and linear range was $\left(1 \times 10^{-5}-1 \times 10^{-2}\right) \mathrm{M}$ for both electrodes. These electrodes were successfully applied for determination of TFPH in pure and pharmaceutical preparations form.
\end{abstract}

\section{Introduction}

Phenothiazine derivatives group has involved in being contain heterogeneous rings. These rings have a sulfur and nitrogen atoms. Among the most important of these derivatives is Trifluoperazine Hydrochloride(TFPH): 10-[3-(4methylpiperazin-1-yl)propyl]-2 (trifluoromethyl)-10H-phenothiazine hydrochloride [1]. Its structure is $\mathrm{C} 21 \mathrm{H} 24 \mathrm{~F} 3 \mathrm{~N} 3 \mathrm{~S} .2 \mathrm{HCl}$, and a molecular weight of $480.415 \mathrm{~g} / \mathrm{mole}$ and its chemical structure is shown in Fig(1). It is a white crystalline powder of melting point 196$199{ }^{\circ} \mathrm{C}$ with high solubility in water and alcohol and disintegrate when exposed to light or air[2]. It mainly acts on dopamine receptor. The primary medication of TFPH is for schizophrenia [3]. It is widely used to control some psychotic disturbances such as depression, agitation, anxiety, psychosis and acute confusional state[4]. Different methods have been reported for the determination of TFPH drug in products and biological samples such as high-performance liquid chroma-tography (HPLC) [5,6], spectrophotometry[7-9], fluorometry[10], capillary electrophoresis[11], 
voltammetry[12], atomic absorption[13] and flow injection analysis[14-16]. However, many of these methods are complicated and time consuming, or require expensive equipment. Thus, there is a need for simple, low-cost, sensitive and rapid alternative methods for the determination of TFPH in pharmaceutical formulations. In the present work, a new membrane electrodes (Coated Carbon) were prepared based on incorporation of an ion pair complex of (PTA) and (PMA) with TFPH in a PVC matrix plasticizer. Both sensors (TFPHPTA) and (TFPH-PMA) show low detection limit, high sensitivity, good selectivity, fast response time, long life span and application for accurate determination of TFPH in pharmaceutical preparations.

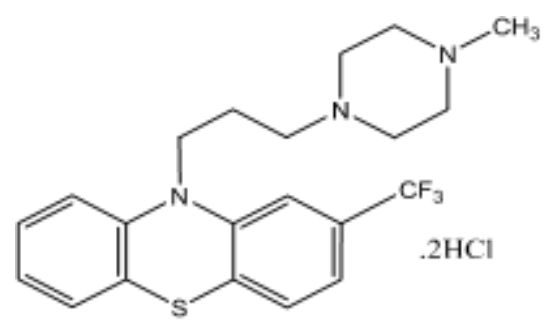

Fig. 1 Chemical structure of Trifluoperazine hydrochloride (TFPH).

\section{Experimental}

Reagents and materials

All chemicals were of analytical reagent grade unless otherwise specified. Distilled water was used for the preparation of stock solutions. TFPH was provided by SDI Samara, (Iraq), Di butyl phthalate (DBP) was supplied from Merck (Germany), Poly vinyl chloride (PVC) high molecular weight was supplied from Fluka, Carbon rod was supplied from Ultra carbon com, Tetra hydro furan.(THF) was purchased from Aldrich (USA). Phosphomolybdic acid (PMA) was obtained from BHD( England) and Phosphotungstic acid (PTA) was obtained from Merck (Germany) . A stock solution $0.1 \mathrm{M}$ of TFPH drug was prepared by dissolving $0.480 \mathrm{~g}$ in $100 \mathrm{ml}$ distilled water. Dilute solutions $\left(1 \times 10^{-}\right.$ ${ }^{6}$ to $1 \times 10^{-2}$ ) $\mathrm{M}$ of TFPH drug were prepared by appropriate diluting the stock solution with distilled water. SALABED tablets (1 mg TFPH) SDI Samara(Iraq) and STELLASIL tablets (5 mg TFPH) KAHIRA PHARM. \& CHEM. IND. CO. CAIRO (Egypt) were purchased from local pharmacies.

\section{Apparatus}

Laboratory potential measurements were performed using HANNA instruments301 $\mathrm{pH}$ meter, Jenway3545 pH meter, calomel electrodes No 13-639-52, Fisher Sientific Co. (Germany). Elemental analysis CHN ElementarIsoprime100-Germany was also used.

Sample preparation

Ten tablets of STELLASIL $5 \mathrm{mg} / \mathrm{tablet}$ (the total tablets weight $3.8079 \mathrm{~g}$ ) and Ten tablets of SALABED $1 \mathrm{mg} /$ tablet (the total tablets weight $2.1797 \mathrm{~g})$ were finely powdered and mixed homogeneously, (0.3807)g of STELLASIL and (1.0895)g of SALABED powder was dissolved in distilled water in a $100 \mathrm{~mL}$ beaker. The solution was then filtered through Whatman filter paper No. 42 and the volume was completed to the mark with water in a $100-\mathrm{mL}$ volumetric flask. The quantity of TFPH was determined by direct and standard-addition methods.

Stock Solutions of Interfering Ions:

Solutions of $1.010^{-3} \mathrm{~mol} \mathrm{~L}^{-1}$ for each of $\mathrm{HCl}$, $\mathrm{NaOH}, \mathrm{NaCl}, \mathrm{BaCl}_{2} .2 \mathrm{H}_{2} \mathrm{O}, \mathrm{CaCl}_{2} \cdot 2 \mathrm{H}_{2} \mathrm{O}$, $\mathrm{NH}_{4} \mathrm{Cl}, \mathrm{Fe}\left(\mathrm{NO}_{3}\right)_{3} .9 \mathrm{H}_{2} \mathrm{O}$, Fructose, Cholesterol , Uric acid, Methyl paraben(M.H.B), Propyl paraben(P.H.B), Talc, Titanium dioxide, Mg.stearate, were prepared by dissolving appropriate amount of these materials in $50 \mathrm{ml}$ of distilled water in volumetric flasks.

Preparation of ion-pairs 
The ion-pairs were prepared by mixing $25 \mathrm{~mL}$ of equimolar of $1 \times 10^{-2} \mathrm{M}$ TFPH to $25 \mathrm{~mL}$ of either PTA or PMA, a grey and brown precipitate of TFPH-PTA and TFPH-PMA were formed. The precipitate was filtered through Whatman filter paper No. 42, and washed with distilled water several times. The precipitate was left $24 \mathrm{~h}$ to dry at room temperature. Preparation of Coated Carbon Sensor

The two sensors were prepared by using a pure carbon rod $4.0 \mathrm{~cm}$ length and $4.0 \mathrm{~mm}$ diameter using a tight polyethylene tube. The sensors surface were coated with the active membrane by dipping one end into the coating mixture [ 10 mg ion-pair (TFPH-PTA) or (TFPH-PMA), 190 mg poly vinyl chloride (PVC) , $0.35 \mathrm{~mL}$ plasticizer di butyl phthalate (DBP) and $1 \mathrm{~mL}$ THF] for seven times and allowing to dry in the air for $5 \mathrm{~min}$ each time. The other end of carbon rod was left for connection. The prepared electrode was preconditioned by soaking for 24 $\mathrm{h}$ in $1.0 \times 10^{-3} \mathrm{~mol} \mathrm{~L}{ }^{-1}$ TFPH solution. [17,18].

\section{Results and Discussion}

TFPH-PTA and TFPH-PMA as an electro active compound was used to prepare new sensors. Elemental analysis was carried out to confirm the composition of the ion-pair (TFPHPTA) and (TFPH-PMA). The obtained results revealed 2:1 [TFPH:PMA] and 2:1[TFPH-PTA] ion pair as indicated in Table(1). The potentiometeric response characteristics based on (TFPH-PTA) and (TFPH-PMA) and DBP plasticizers, in PVC matrix were examined.

Calibration plot of the fabricated electrodes

The fabricated electrodes sensors were immersed along with Calomel reference electrode in solutions of TFPH in the range from $(1 \times 10-6-1 \times 10-2)$ M. The $\mathrm{E}(\mathrm{mV})$ against $\log [\mathrm{TFPH}]$ profile was plotted as shown in Fig(2). The both electrodes show a linear response over the concentration ranges from (1×10-5 - 1×10-2) M with near Nernstian slopes of and (30.67 and 30.26) $\mathrm{mV}$ /decade for PTA and PMA sensors respectively.

\section{Effect of $\mathrm{pH}$}

The effect of $\mathrm{pH}$ on the performance of the tow electrodes was investigated using concentrations of $(1.0 \times 10-4$ and $1.0 \times 10-3) \mathrm{M}$ of TFPH drug at different $\mathrm{pH}$ values (1-10) by addition of small volumes of $\mathrm{HCl}$ and/or $\mathrm{NaOH}$ solution (0.1-1 $\mathrm{M}$ of each). The potential at each $\mathrm{pH}$ value was recorded. It is obvious that, within the $\mathrm{pH}$ range from $(2.7-6.6)$.

The studied electrode potentials are practically independent of $\mathrm{pH}$, and then can be safely used for TFPH determination (Fig.3). However the potential decreases gradually at $\mathrm{pH}$ values higher than 6.6 , the decrease may be attributed to hydroxide ions that react with TFPH drug leading to formation of free drug in the test solution, neutral species, which could not be penetrated into the membrane [19] and $\mathrm{pH}$ values lower than 2.7 , the potential readings decrease which can be related to interference of hydronium ion [20].

\section{Effect of temperature}

The change of potential was measured by changing the temperature of the drug solution from (25-70) ${ }^{\circ} \mathrm{C}$ for concentration of $10-2 \mathrm{M}$. The relationship between the temperature and the measured potential was plotted. The results in (Fig 4) showed that the appropriate working temperature is $(25-50)^{\circ} \mathrm{C}$ for (TFPH-PMA) and $(25-55)^{\circ} \mathrm{C}$ for (TFPH-PTA) .The increase in potential with the increase of temperature is may due to the increase in surface area of the membrane resulting in easier permeation and equilibration.

Selectivity of the studied sensors

The selectivity coefficients (log K) of the studied sensors were determined employing separate solution method (SSM) [21, 22]. In SSM, the potential of cell comprising the 
membrane electrode and a reference electrode is measured in two separate solutions, where (TFPH ions) and (interfering ion) at the same activity. Selectivity coefficients were calculated using Nicolsky equation [22] : $\log K=(E j-$ $\mathrm{Ei} / \mathrm{S}$ where $\mathrm{Ei}$ is the potential measured in $1 \times 10-3 \mathrm{~mol} / \mathrm{L}$ TFPH, $\mathrm{Ej}$ the potential measured in $1 \times 10-3 \mathrm{~mol} / \mathrm{L}$ of the interfering ion or compound, $\mathrm{S}$ is the slope of the calibration plot.

The $\mathrm{K}$ value represents the difference in potential in the presence of interfering ion (j) and when (j) is not present. When the value is less than 1 this indicates that the electrode shows low response to the interfering ions. The results of selectivity are shown on table (2). The K values shows a very high selectivity of the electrodes towards the TFPH.

\section{Life time}

For the determination of the storage stability, sensors fabricated in the same procedure have been used in the potentiometric calibrations under optimum conditions, several times every week. The performance of the electrode has been tested by potentiometric calibration of TFPH standard solutions on different days. The results showed that both electrodes have life time of 48 days. After this time, the slope and the detection limit of the sensor will decrease. Loss of the plasticizer, carrier or ionic site from the polymeric film, as a result of leaching into the sample, is the primary reason for the limited life time of the sensors [23].

\section{Validation of the proposed method:-}

1-Limit of detection and linearity

Linearity of an electro analytical method is a measure of how well calibration plot of electro analytical response versus concentration approximates a straight line [24]. The standard calibration graph was obtained using four concentrations of the standard TFPH drug.It was found that a linear relationship exist between the electrode potential $(\mathrm{mV})$ and the $\log [\mathrm{TFPH}]$. The regression data, correlation coefficients (R2) and other statistical parameter are listed in Table (3). Limit of detection(LOD) is the lowest quantity of the investigated compound in a sample that can be detected. The values of LOD indicate that the sensors under investigation are highly sensitive and can be applied for determination of small amounts of TFPH drug.

\section{2- Precision and Accuracy}

To evaluate the accuracy and precision of the proposed method, pure drug and pharmaceutical preparations solutions (within the working limits) was analyzed, each solution was repeated (5) times. Precision and accuracy were based on the calculated relative standard deviation (RSD\%) and percent relative error (RE $\%)$. The results( table 7) show that these methods have reasonable precision and accuracy.

\section{3- Robustness and Ruggedness}

The robustness method of the (TFPH-PMA) and (TFPH-PTA) was examined by changing the aqueous solution to acetate buffer $\mathrm{pH}$ (3.18). The results of this investigation are shown in table(4) and figure (5). The ruggedness was checked by using another model of $\mathrm{pH}$-meter (Jenway, 3545). The results of this investigation are shown in table(5) and figure (6).

It is clear from the results that The statistical and analytical parameters for new TFPH-PTA and TFPH-PMA electrodes are unaffected when using buffer solution (robustness) or using another instrument (ruggedness)

\section{Applications :}

Determination of TFPH in its pharmaceutical preparation.

Three methods are applied for quantitative analysis using the proposed electrodes. These methods comprise: (1) calibration curve method (direct potentiometry) and (2) Standard Addition (3) Content Uniformity Assay Test: 
1- calibration curve method

A calibration curve is a general method for determination of the concentration of a substance in unknown sample by comparing the response of the unknown to those of a set of standard samples of known concentration. Pure drug and Pharmaceutical formulation (tablets) TFPH drug was determined by the calibration curve method. The results are shown in table(6).

\section{2- Standard Addition Method}

The standard addition method was employed for determination of mentioned drugs in its dosage forms. The method based on adding small volume of the investigated drug solution and the sensor potential was recorded . Both fabricated electrodes were immersed into $10 \mathrm{~mL}$ drug test solution of unknown concentration and the equilibrium potential of E1 was recorded. Then $(1-4) \mathrm{mL}$ of the standard drug solution $(1 \times 10$ 2)M was added into the test solution and the equilibrium potential E2 was recorded each solution were completed to constant volume[25]. The results are shown in table (7). The high values of recovery and low values of relative error indicate the applicability of the new constructed electrodes for the determination of TFPH.

\section{3-Content Uniformity Assay Test}

To study the content uniformity assay test for pharmaceutical preparations of TFPH drug, 10 individual tablets STELLASIL (5mg) were placed in separate $100-\mathrm{mL}$ beakers and dissolved in $100 \mathrm{~mL}$ distilled water to obtain $(1.0 \times 10-4) \mathrm{M}$ and also 10 individual tablets SALABED (1mg) were placed in separate 25$\mathrm{mL}$ beakers and dissolved in $20 \mathrm{~mL}$ distilled water to obtain $(1.0 \times 10-4) \mathrm{M}$ and the potential of each solution was recorded using the fabricated sensors. The mean potential was used to evaluate the content uniformity applying of calibration graph. The results are shown in table $(8)$

Comparison with previous reported electrodes

The performance characteristics of the proposed electrodes and those previously reported electrodes are compiled in table (9) for comparison. It is clear that detection limit is lower, working range is wider, and their life time is longer than the other electrodes

\section{Conclusion}

The proposed method introduced an ion selective electrodes for the determination of TFPH based on PVC plasticized with DBP and using PTA or PMA as active materials. These electrodes showed a successful application with low limit of detection and good recovery. The electrodes also showed long life time, good selectivity and reasonable working concentration ranges.

\section{REFERANCES}

1. Budawari S., The Merck Index, 13th Edition, Merck and Co. Inc. Whitehouse Station. NJ, 2001, 630, 32- 1631.

2. khammas Z. A-A., Rashid R. A. science journal of analytical chemistry ,2015, 3,5 , 6170.

3. Bhaskar R. C. M., Subba R. G. V., Ananda K. R. .N , international journal of scientific and research publications $2012,2,8,1-5$.

4. [Online] available: http://en.wikipedia.org/wiki/ Trifluoperazine.

5. Tanaka E., Nakamura T. , Terada M., Shinozuka T., Hashimoto C., Kurihara K., Honda K., J. Chromatogr., B, 2007, 854, 116120.

6. Cruz-Vera M., Lucena R., Cárdenas S., Valcárcel M. , J. Chromatogr., B, 2009, 877, 37-42. 
7. Nagaraja P., Dinesh N. D., Gowda N. M. M., Rangappa K. S., Anal. Sci., 2000, 16, $1127-$ 1131

8. El-Gindy A., El-Zeany B. , Tamer A., Shabana M. M. , J. Pharm. Biomed. Anal., 2001, 26, 203-210.

9. Revanasiddappa H. D., Veena M. A. , J. Anal. Chem., 2008, 63, 140-144.

10. Yang G. J. , Qu X. L.. M. Shen, Qu Q. S., Wang C. Y. , Zhu A. P., Hu X. Y., J. Fluoresc., 2007, 17, 119-126.

11. Muijselaar P. G. H. M., Claessens H. A., Cramers C. A.,J. Chromatogr., A, 1996, 735, 395-402.

12. D. Stanković , T. Dimitrijević , D. Kuzmanović M. P. Krstić , B. B. Petković , RSC Advances, 2015 , 5 , 107058-107063.

13. Ameen W. Q., Zuhair A. K., E-Journal of chemistry 2010, 7,1, 433-441.

14. Pérez-Ruiz T., Martínez-Lozano C., Sanz A. , Teresa S. M. M., Lab Autom Inform Manag., 1999, 34, 149-158.

15. Ruedas R. M. J. , Ruiz M. A. ,Molina D. A., J Pharm Biomed Anal., 2004, 35,5, 1027-1034.

16. Idris A. M. , J Pharmacol Toxicol Methods, 2007, 56, 330-335.
17. Al-Amri F. M. G., Alarfaj N. A., Aly F. A. J. Electrochem. Sci., 2013, 8, 10044-10058.

18. El-Tohamy M., Razeq S., El-Maamly M., Shalaby A. IJMCA. $2014,4,130-140$.

19. Khalil, S. Analyst, 1999 ,124(2), 139-142.

20. El-Ansary A.L., Issa Y.M. , Tag-Eldin A.S., Electroanalysis., 2001, 13, 1203-1208.

21. Cosofret V.V., Buck R.P. , Pharmaceutical Applications of Membrane Sensors, 1992 „1, 50-284.

22. Vytras K. , Journal of Pharmaceutical and Biomedical Analysis, 1989 , 7 ,789-812.

23. Faridbod F., Ganjali M. R., Larijani B., Norouzi P., Riahi S., Mirnaghi F. Sensors, 2007,7,12, 3119-3135.

24. Gumustas M., Ozkan A.S. ,The Open Analytical Chemical Journal, 2011, 5, 1-21

25. Buck R. P., Linder E., Pure Appl. Chem., 1994, 66, 2527-2536.

26. Hassan A. K. , Ameen S. T. ,Saad B. ,AlAragi S. M., Journal Analytical Sciences ,2009,25,1295-1299.

27. Al-Samarrai I. T. H. A. , MSc.Thesis ,2010 ,university of Tikrit, Iraq

(Table 1) Elemental analysis of the ( TFPH-PMA) and (TFPH-PTA) ion pair

\begin{tabular}{|c|c|c|c|c|c|c|}
\hline \multirow{2}{*}{$\begin{array}{l}\text { Element } \\
\text { analysis }\end{array}$} & \multicolumn{3}{|c|}{ TFPH-PTA } & \multicolumn{3}{|c|}{ TFPH-PMA } \\
\hline & $\% \mathrm{c}$ & $\% \mathrm{~h}$ & $\% \mathrm{n}$ & $\% \mathrm{c}$ & $\% \mathrm{~h}$ & $\% \mathrm{n}$ \\
\hline \multirow{3}{*}{$\begin{array}{l}\text { Found } \\
\text { Calculated } \\
\text { Formula }\end{array}$} & 10.12 & 3.57 & 1.77 & 16.93 & 2.86 & 2.86 \\
\hline & 10.40 & 3.41 & 1.74 & 16.97 & 2.53 & 2.83 \\
\hline & $\begin{array}{l}{\left[\mathrm{C}_{21} \mathrm{H}\right.} \\
5 \mathrm{H}_{2} \mathrm{O}\end{array}$ & ${ }_{2} \mathrm{~N}_{3} \mathrm{~F}_{3}$ & $\left.\mathrm{~W}_{12} \mathrm{O}_{40}\right] .5$ & $\begin{array}{l}{\left[\mathrm{C}_{21} \mathrm{H}\right.} \\
10 \mathrm{H}_{2} \mathrm{C}\end{array}$ & $\left.{ }_{3} \mathrm{~F}_{3} \mathrm{~S}\right]_{2}$ & $\left.\left.\mathrm{MO}_{12} \mathrm{O}_{40}\right)\right]$ \\
\hline
\end{tabular}




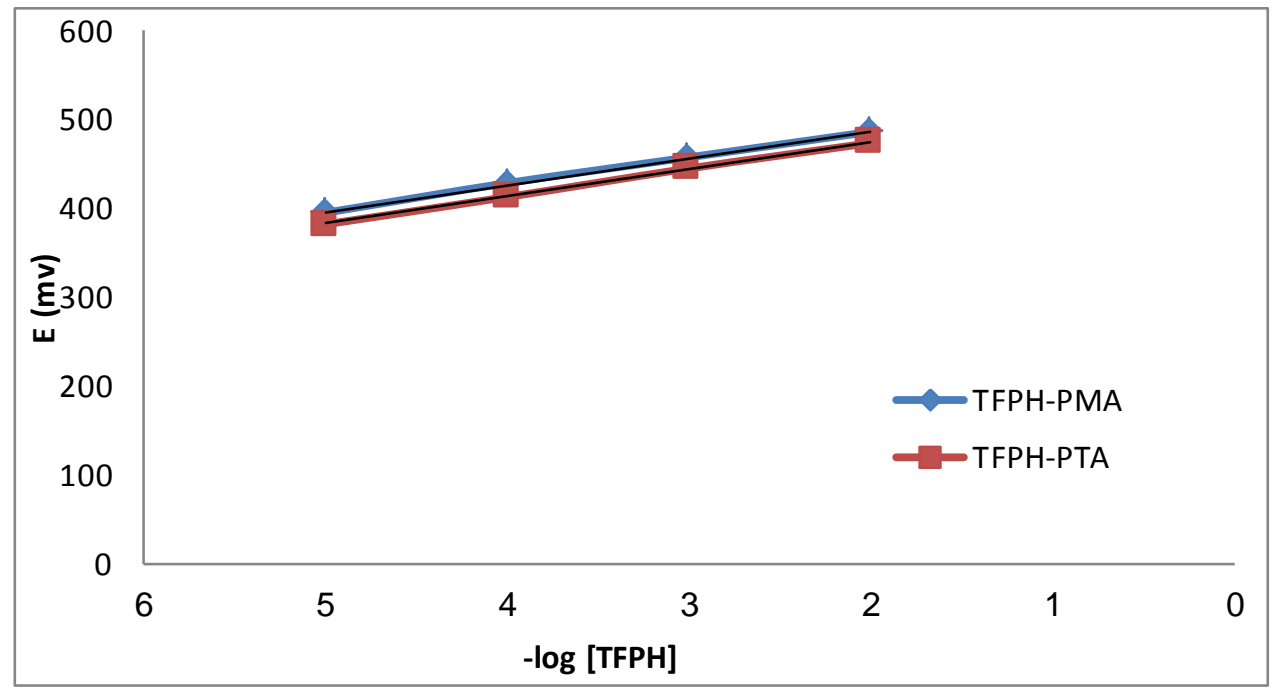

Figure (2): Standard curve of TFPH using TFPH-PTA and TFPH-PMA Electrodes

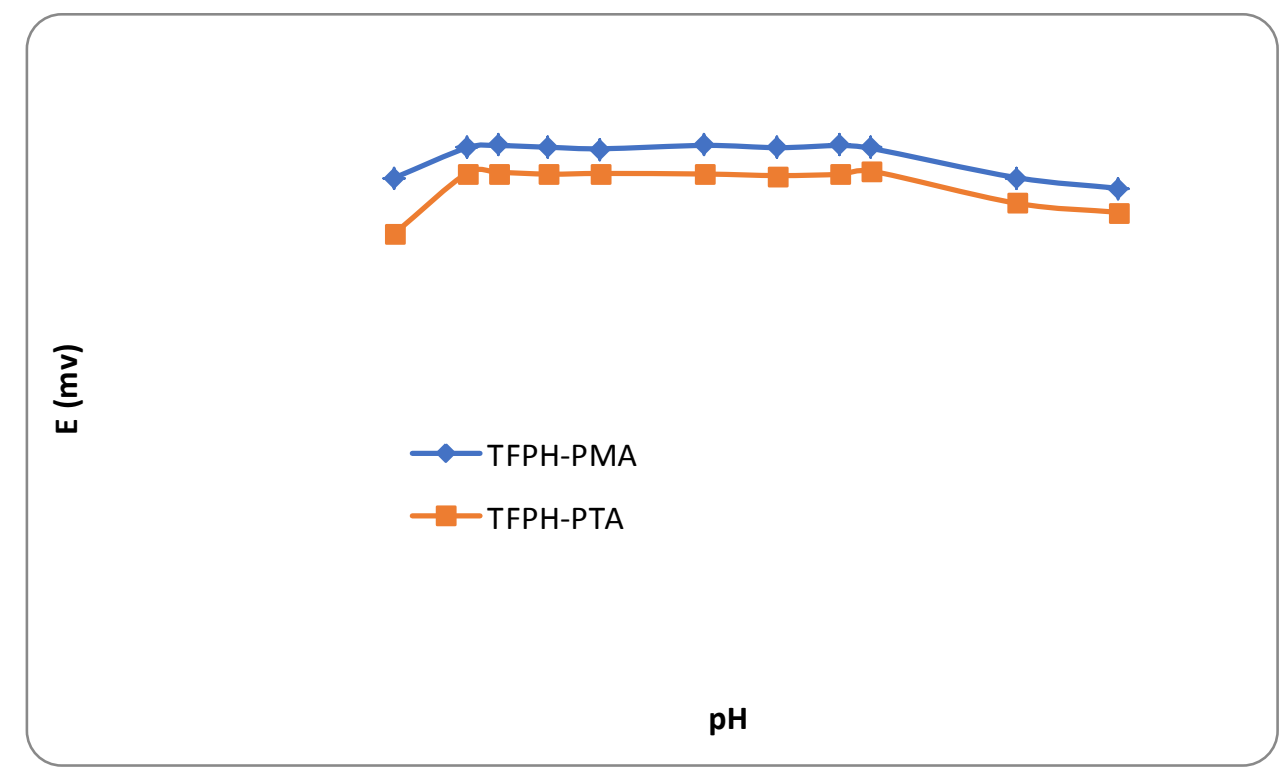

Figure (3): Effect of $\mathrm{pH}$ on the response of TFPH-PTA and TFPH-PMA electrodes using TFPH solution $(1 \times 10-3) \mathrm{M}$ 


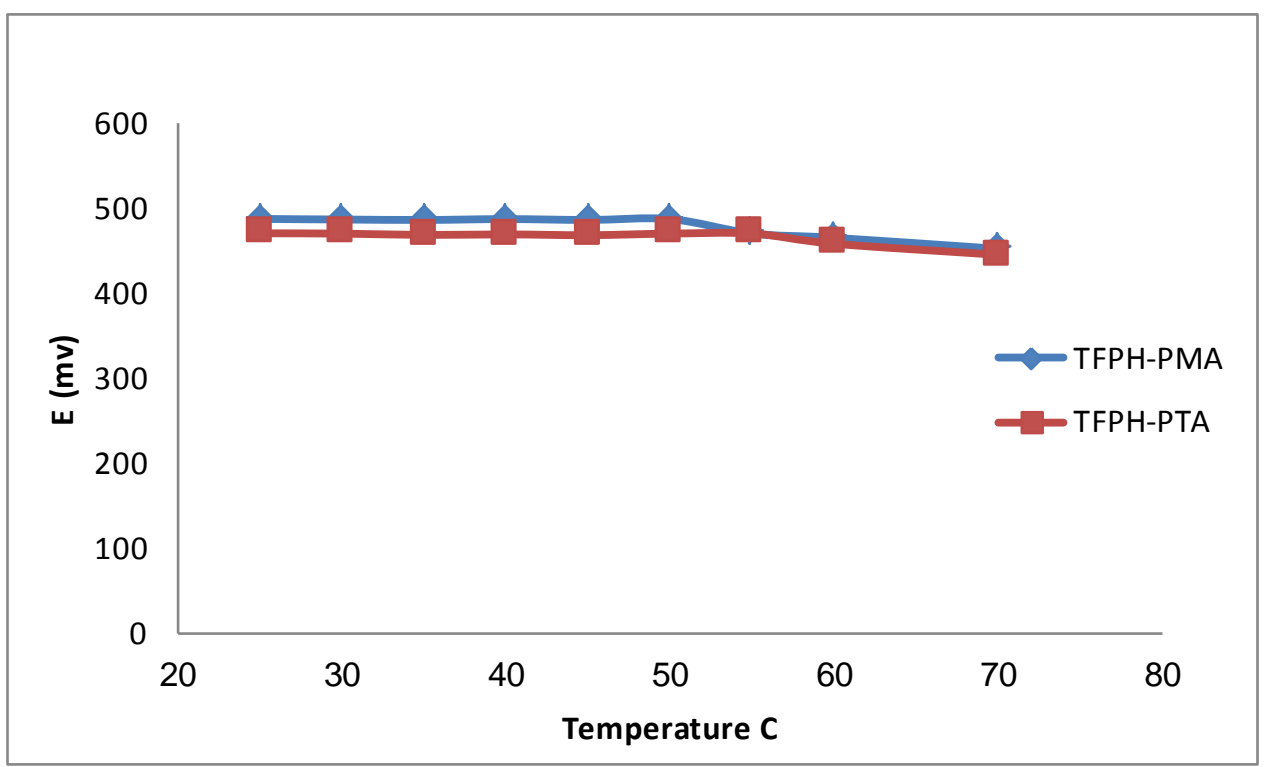

Figure (4): Effect of temperature on the response of TFPH-PMA and TFPH-PTA electrodes

Table (2) K value of both TFPH-PMA and TFPH-PTA electrodes

\begin{tabular}{l|ll}
$\begin{array}{l}\text { INTERFERING } \\
\text { ION OR } \\
\text { COMPOUND }\end{array}$ & \\
\hline & & \\
$\mathrm{NA}^{+1}$ & $2.41 \times 10^{-3}$ & $\mathrm{~K}$ \\
$\mathrm{H}^{+1}$ & $1.23 \times 10^{-2}$ & $4.1876 \times 10^{-2}$ \\
$\mathrm{NH}^{+1}$ & $1.90 \times 10^{-2}$ & $4.729 \times 10^{-2}$ \\
$\mathrm{BA}^{+2}$ & $4.80 \times 10^{-2}$ & $1.680 \times 10^{-2}$ \\
$\mathrm{CA}^{+2}$ & $4.23 \times 10^{-2}$ & $1.680 \times 10^{-2}$ \\
$\mathrm{FE}^{+3}$ & $3.83 \times 10^{-2}$ & $3.282 \times 10^{-2}$ \\
$\mathrm{CL}^{-1}$ & $3.77 \times 10^{-2}$ & $4.802 \times 10^{-2}$ \\
$\mathrm{FRUCTOSE}^{-2}$ & $2.42 \times 10^{-2}$ & $4.124 \times 10^{-2}$ \\
$\mathrm{CHOLESTEROL}^{-2}$ & $2.84 \times 10^{-3}$ & $2.421 \times 10^{-2}$ \\
$\mathrm{URIC}^{-2}$ ACID & $1.99 \times 10^{-3}$ & $2.421 \times 10^{-2}$ \\
$\mathrm{MG}^{+2}$ & $5.29 \times 10^{-3}$ & $3.568 \times 10^{-2}$ \\
& & $2.906 \times 10^{-2}$
\end{tabular}




\begin{tabular}{l|ll} 
M.H.B & $5.97 \times 10^{-3}$ & $2.348 \times 10^{-2}$ \\
P.H.B & $5.88 \times 10^{-3}$ & $2.421 \times 10^{-2}$ \\
TALC & $4.73 \times 10^{-3}$ & $1.869 \times 10^{-2}$ \\
$\mathrm{TI}^{+4}$ & $6.89 \times 10^{-3}$ & $1.317 \times 10^{-2}$
\end{tabular}

Table(3): statistical and analytical parameters for new TFPH-PTA and TFPH-PMA constructed electrodes

\begin{tabular}{l|cc}
\multicolumn{1}{c|}{ PARAMETERS } & TFPH-PTA & TFPH-PMA \\
\hline SLOPE (MV DECADE-1) & 30.67 & 30.26 \\
CORRELATION & 0.9980 & 0.9990 \\
COEFFICIENT $\left(\mathrm{R}^{2}\right)$ & & $1 \times 10^{-5}-1 \times 10^{-2}$ \\
LINEAR RANGE, $\mathrm{M}$ & $1 \times 10^{-5}-1 \times 10^{-2}$ & $4.56 \times 10^{-6}$ \\
DETECTION LIMIT ,M & $4.99 \times 10^{-6}$ & $2.7-6.6$ \\
WORKING PH RANGE & $2.7-6.6$ & $25-50$ \\
OPTIMUM TEMPERATURE $^{\text {RANGE }}{ }^{\circ} \mathrm{C}$ & $25-55$ & 48 \\
LIFE TIME (DAY) & 48 &
\end{tabular}

Table (4)The statistical and analytical parameters for new TFPH-PTA and TFPH-PMA electrodes when using acetate buffer $(\mathrm{pH}=3.18)$

\begin{tabular}{|c|c|c|}
\hline PARAMETER & TFPH-PMA & TFPH-PTA \\
\hline SLOPE(MV DECADE ${ }^{-1}$ ) & 29.82 & 31.29 \\
\hline CORRELATION & 0.9990 & 0.9990 \\
\hline COEFFICIENT $\mathrm{R}^{2}$ & & \\
\hline LINEAR RANGE M & $1 \times 10^{-5}-1 \times 10^{-2}$ & $1 \times 10^{-5}-1 \times 10^{-2}$ \\
\hline LIMIT OF DETECTION, M & $4.765 \times 10^{-6}$ & $4.879 \times 10^{-6}$ \\
\hline$\%$ RECOVERY \pm SD & $99.85 \pm 0.289$ & $99.87 \pm 0.530$ \\
\hline VARIANCE & 0.083 & 0.280 \\
\hline$\% \mathrm{RSD}$ & 0.289 & 0.530 \\
\hline$\% \mathrm{RE}$ & -0.15 & -0.13 \\
\hline
\end{tabular}




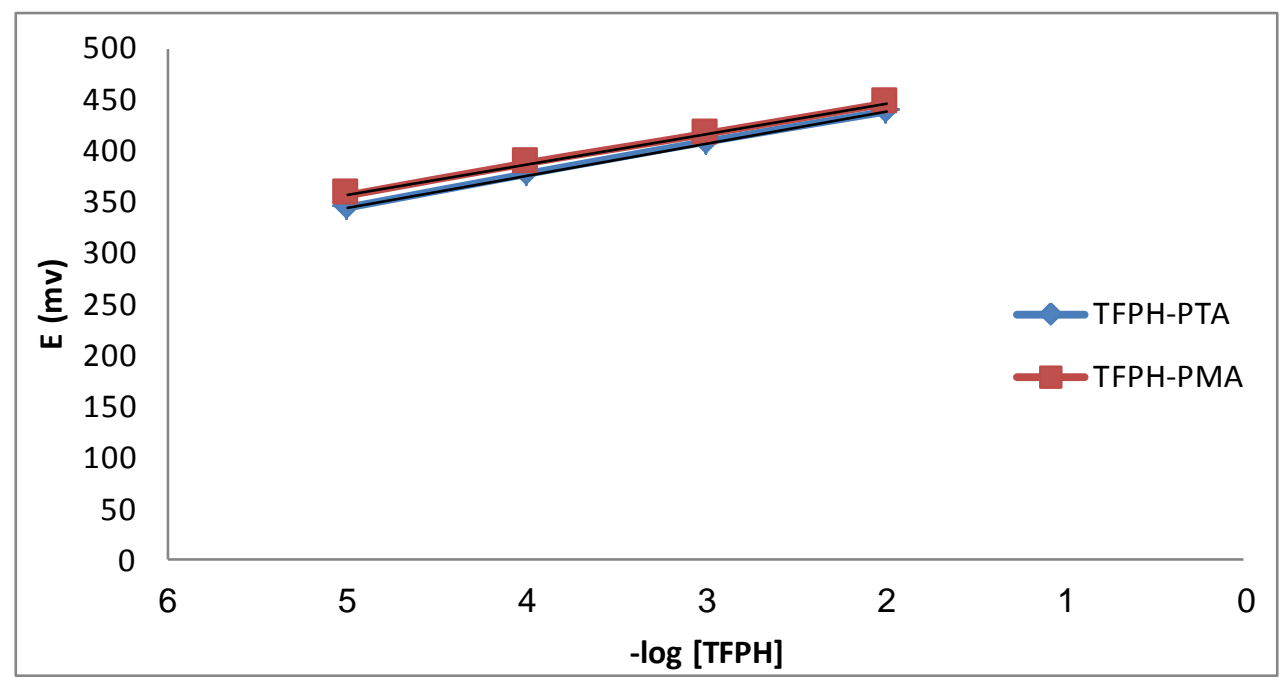

Figure (5) The effect of acetate buffer(robustness) on response of the TFPH-PTA and TFPH-PMA electrode

Table (5)The statistical and analytical parameters for new TFPH-PTA and TFPH-PMA electrodes when using another model of $\mathrm{pH}$-meter

\begin{tabular}{|c|c|c|}
\hline PARAMETER & TFPH-PMA & TFPH-PTA \\
\hline SLOPE(MV DECADE $\left.{ }^{-1}\right)$ & 29.77 & 32.56 \\
\hline CORRELATION & 0.9990 & 0.9980 \\
\hline COEFFICIENT $\mathrm{R}^{2}$ & & \\
\hline LINEAR RANGE M & $1 \times 10^{-5}-1 \times 10^{-2}$ & $1 \times 10^{-5}-1 \times 10^{-2}$ \\
\hline LIMIT OF DETECTION & $4.70424 \times 10^{-6}$ & $5.80114 x^{-6}$ \\
\hline M & & \\
\hline$\%$ RECOVERY \pm SD & $99.38 \pm 0.558$ & $99.06 \pm 0.062$ \\
\hline VARIANCE & 0.311 & 0.003 \\
\hline$\% \mathrm{RSD}$ & 0.561 & 0.062 \\
\hline$\% \mathrm{RE}$ & -0.62 & -0.94 \\
\hline
\end{tabular}




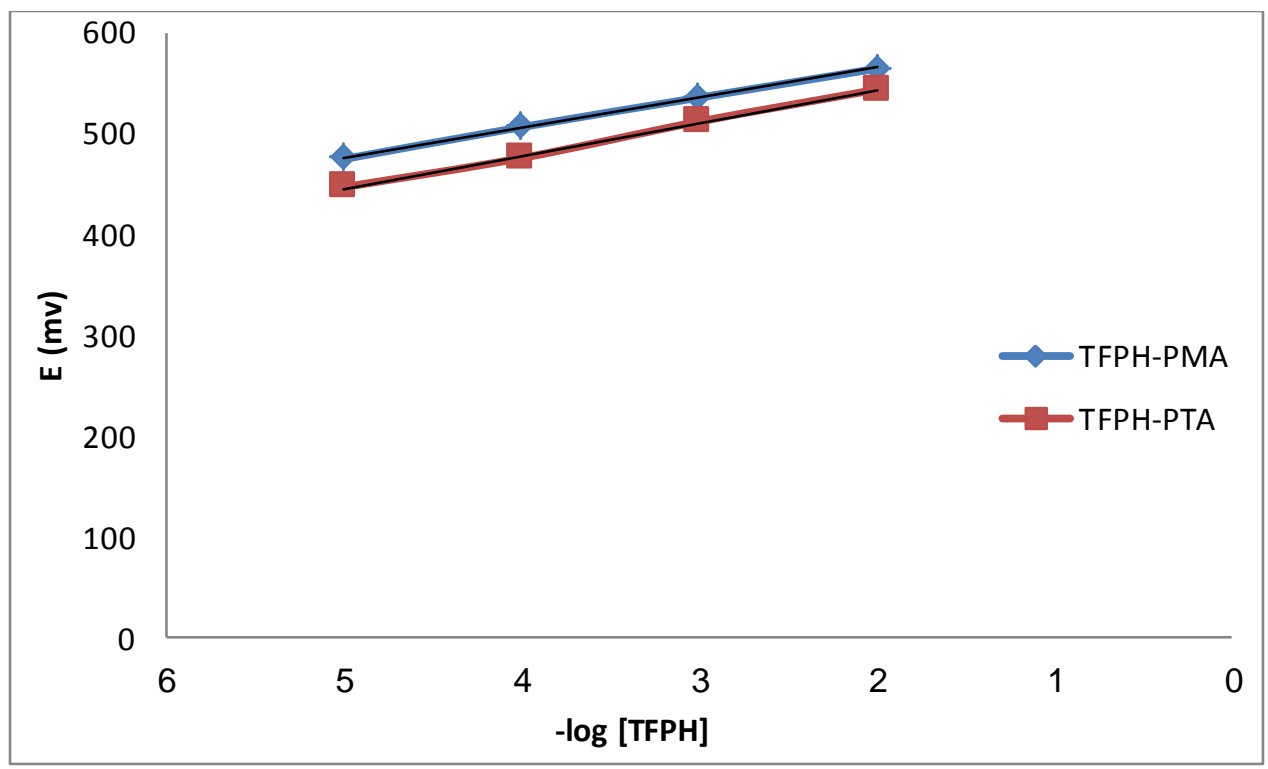

Figure (6) Test of ruggedness of TFPH-PTA and TFPH-PMA electrode by using another model of pHmeter (Jenway, 3545)

Table (6): calibration curve methods for TFPH-PTA and TFPH-PMA electrode

\begin{tabular}{|c|c|c|c|c|c|c|}
\hline SAMPLE & & TFPH-PMA- & $\mathrm{BP}$ & & TFPH -PTA & DBP \\
\hline & Taken & Found & $\%$ & Taken & Found & $\%$ \\
\hline & TFPH] M & & Recovery & [TFPH] M & & RECOVE \\
\hline & & & & & & RY \\
\hline & $1.0 \times 10^{-2}$ & $1.0020 \times 10$ & 100.20 & $1.0 \times 10^{-2}$ & $9.984 \times 10^{-3}$ & 99.84 \\
\hline Pure drug & $1.0 \times 10^{-3}$ & -2 & 99.40 & $1.0 \times 10^{-3}$ & $9.996 \times 10^{-3}$ & 99.96 \\
\hline & $1.0 \times 10^{-4}$ & $9.940 \times 10^{-4}$ & 99.23 & $1.0 \times 10^{-4}$ & $9.974 \times 10^{-5}$ & 99.74 \\
\hline & $1.0 \times 10^{-5}$ & $9.923 \times 10^{-5}$ & 98.35 & $1.0 \times 10^{-5}$ & $9.920 \times 10^{-6}$ & 99.20 \\
\hline & & $9.835 \times 10^{-6}$ & & & & \\
\hline Mean $\pm S D \%$ & & $99.29 \pm 0.3$ & & & $99.68 \pm 0.18$ & \\
\hline $\mathrm{n}$ & & 5 & & & 5 & \\
\hline Variance & & 0.147 & & & 0.034 & \\
\hline $\mathrm{RE} \%$ & & -0.71 & & & -0.32 & \\
\hline RSD \% & & 0.386 & & & 0.185 & \\
\hline Salabed & $1.0 \times 10^{-4}$ & $9.803 \times 10^{-5}$ & 98.03 & $1.0 \times 10^{-4}$ & $9.991 \times 10^{-5}$ & 99.11 \\
\hline (1 mg) & $1.0 \times 10^{-5}$ & $9.986 \times 10^{-6}$ & 99.86 & $1.0 \times 10^{-5}$ & $9.964 \times 10^{-6}$ & 99.64 \\
\hline
\end{tabular}




\begin{tabular}{|c|c|c|c|c|c|c|}
\hline Mean $\pm S D \%$ & \multicolumn{3}{|c|}{$98.94 \pm 0.915$} & \multicolumn{3}{|c|}{$99.37 \pm 0.385$} \\
\hline $\mathrm{n}$ & \multicolumn{3}{|c|}{5} & \multicolumn{3}{|c|}{5} \\
\hline Variance & \multicolumn{3}{|c|}{0.837} & \multicolumn{3}{|c|}{0.148} \\
\hline RE\% & \multicolumn{3}{|c|}{-1.06} & \multicolumn{3}{|c|}{-0.63} \\
\hline RSD \% & \multicolumn{3}{|c|}{0.924} & \multicolumn{3}{|c|}{0.387} \\
\hline Stellasil & $1.0 \times 10^{-4}$ & $9.971 \times 10^{-5}$ & 99.71 & $1.0 \times 10^{-4}$ & $9.925 \times 10^{-5}$ & 99.25 \\
\hline (5 mg) & $1.0 \times 10^{-5}$ & $9.864 \times 10^{-6}$ & 98.64 & $1.0 \times 10^{-5}$ & $9.843 \times 10^{-6}$ & 98.43 \\
\hline Mean $\pm S D \%$ & \multicolumn{3}{|c|}{$99.17 \pm 0.535$} & \multicolumn{3}{|c|}{$98.84 \pm 0.910$} \\
\hline $\mathrm{n}$ & \multicolumn{3}{|c|}{5} & \multicolumn{3}{|c|}{5} \\
\hline Variance & \multicolumn{3}{|c|}{0.286} & \multicolumn{3}{|c|}{0.828} \\
\hline RE\% & \multicolumn{3}{|c|}{-0.83} & \multicolumn{3}{|c|}{-1.16} \\
\hline RSD $\%$ & \multicolumn{3}{|c|}{0.539} & \multicolumn{3}{|c|}{0.920} \\
\hline
\end{tabular}

Table (7): standard addition methods for TFPH-PTA and TFPH-PMA electrode

\begin{tabular}{|c|c|c|c|c|c|c|}
\hline \multirow[t]{2}{*}{ SAMPLE } & \multicolumn{3}{|c|}{ TFPH-PMA } & \multicolumn{3}{|c|}{ TFPH-PTA } \\
\hline & $\begin{array}{l}\text { Taken } \\
\text { [SILC] } \\
\mathrm{M}\end{array}$ & $\begin{array}{c}\text { Found } \\
{[\text { SILC] M }}\end{array}$ & $\begin{array}{c}\% \\
\text { Recovery }\end{array}$ & $\begin{array}{c}\text { Taken } \\
\text { [SILC] } \\
\mathrm{M}\end{array}$ & $\begin{array}{c}\text { Found } \\
{[\text { SILC] M }}\end{array}$ & $\begin{array}{c}\% \\
\text { RECOVERY }\end{array}$ \\
\hline $\begin{array}{l}\text { STELLASIL } \\
(5 \mathrm{mg})\end{array}$ & $1.0 \times 10^{-4}$ & $1.0098 \times 10^{-4}$ & 100.98 & $1.0 \times 10^{-4}$ & $9.934 \times 10^{-5}$ & 99.34 \\
\hline$\% \mathrm{RE}$ & & 0.98 & & & -0.66 & \\
\hline $\begin{array}{l}\text { SALABED } \\
\text { (1mg) }\end{array}$ & $1.0 \times 10^{-4}$ & $9.863 \times 10^{-5}$ & 98.63 & $1.0 \times 10^{-4}$ & $\begin{array}{c}1.0018 \\
\times 10^{-4}\end{array}$ & 100.18 \\
\hline$\% \mathrm{RE}$ & & -1.37 & & & 0.18 & \\
\hline
\end{tabular}

Table(8) The results of Content uniformity Assay

\begin{tabular}{|c|c|c|c|c|c|}
\hline \multirow{2}{*}{\multicolumn{2}{|c|}{ STATE }} & STELLASIL (5MG) & \multicolumn{3}{|c|}{ SALABED (1MG) } \\
\hline & & TFPH-PTA & TFPH-PMA & TFPH-PTA & TFPH-PMA \\
\hline & TAKEN CONC. & \multicolumn{4}{|c|}{$1.0 \times 10^{-4}$} \\
\hline & FOUND & $9.963 \times 10^{-5}$ & $1.0069 \times 10^{-4}$ & $9.975 \times 10^{-5}$ & $9.860 \times 10^{-5}$ \\
\hline & CONC.* & & & & \\
\hline & $\begin{array}{l}\% \text { RECOVERY* } \\
\pm \text { SD }\end{array}$ & $99.63 \pm 0.379$ & $100.69 \pm 0.409$ & $99.75 \pm 0.475$ & $98.60 \pm 0.399$ \\
\hline (9) & VRAIANCE & 0.143 & 0.167 & 0.225 & 0.159 \\
\hline Com & $\% \mathrm{RSD}$ & 0.380 & 0.406 & 0.476 & 0.404 \\
\hline paris & $\% \mathrm{RE}$ & -0.37 & 0.69 & -0.25 & -1.40 \\
\hline
\end{tabular}


on of the new Coated Carbon electrodes with those previously reported in literature

\begin{tabular}{|c|c|c|c|c|}
\hline PARAMETER & TFPH-PTA & TFPH-PMA & TFPH-PMA & TFPH-AR* \\
\hline $\begin{array}{l}\text { SLOPE, } \\
\text { MV/DECADE }\end{array}$ & 30.67 & 30.26 & 32.11 & 29.40 \\
\hline $\begin{array}{l}\text { LINEAR } \\
\text { CONC. }\end{array}$ & $1 \times 10^{-5}-1 \times 10^{-2}$ & $1 \times 10^{-5}-1 \times 10^{-2}$ & $1 \times 10^{-5}-1 \times 10^{-2}$ & $1 \times 10^{-4}-1 \times 10^{-2}$ \\
\hline RANGE, M & & & & \\
\hline WORKING PH & $2.7-6.6$ & $2.7-6.6$ & $3.0-6.0$ & $2.2-2.6$ \\
\hline $\begin{array}{l}\text { LIMIT OF } \\
\text { DETECTION, } \\
\text { M }\end{array}$ & $4.99 \times 10^{-6}$ & $4.56 \times 10^{-6}$ & $1 \times 10^{-5}$ & $9.0 \times 10^{-8}$ \\
\hline $\begin{array}{ll}\text { LIFE } & \text { TIME } \\
\text {,DAY } & \end{array}$ & 48 & 48 & 28 & 30 \\
\hline $\begin{array}{l}\text { ELECTRODE } \\
\text { TYPE }\end{array}$ & $\begin{array}{c}\text { Coated Carbon } \\
\text { electrodes }\end{array}$ & $\begin{array}{c}\text { Coated Carbon } \\
\text { electrodes }\end{array}$ & $\begin{array}{l}\text { liquid } \\
\text { membrane } \\
\text { electrode }\end{array}$ & $\begin{array}{l}\text { liquid } \\
\text { membrane } \\
\text { electrode }\end{array}$ \\
\hline REF. NO. & present study & present study & [26] & [27] \\
\hline
\end{tabular}

